This manuscript was accepted and published by the Thermochimica Acta.

Publication data of the final, corrected work:

Wu, M.; Várhegyi, G.; Zha Q.: Kinetics of cellulose pyrolysis after a pressurized

heat treatment. Thermochim. Acta 2009, 496, 59-65: doi: 10.1016/j.tca.2009.06.024

\title{
Kinetics of cellulose pyrolysis after a pressurized heat treatment
}

\author{
Mingbo Wu ${ }^{\mathrm{a}}$, Gábor Várhegyi ${ }^{\mathrm{b}, *}$, Qingfang $\mathrm{Zha}^{\mathrm{a}}$ \\ ${ }^{\text {a }}$ State Key Laboratory of Heavy Oil Processing, Heavy Oil Processing Research Institute, China \\ University of Petroleum, Dongying 257061, China \\ ${ }^{\mathrm{b}}$ Institute of Materials and Environmental Chemistry, Chemical Research Center, Hungarian \\ Academy of Sciences, Budapest, Hungary
}

*Corresponding author. Email: varhegyi.gabor@t-online.hu or gvarhegyi@gmail.com

\begin{abstract}
A hot pressure treatment (HPT) converts celluloses into an advantageous feedstock for activated carbon preparation. Other ways of utilization may also emerge in the future. In the present paper the pyrolysis kinetics of three HPT cellulose samples were studied by thermogravimetric analysis (TGA) at linear and stepwise temperature programs. A distributed activation energy model was used assuming two partial reactions. Nine experiments on three samples were evaluated simultaneously by the method of least squares. 20 unknown parameters were determined in this way. Good fits were obtained at the linear and stepwise temperature programs alike. The evaluations were also carried out by non-constant preexponential factors that depended on the activation energy. The considerations and evaluation methods of the paper are hoped to help the investigations of other biomass materials, too. The results showed that part of the cellulose remained unconverted and another part only partially converted at the mildest pretreatment conditions of this study. The cellulose was wholly transformed in the pretreatment when either the pressure or the temperature was increased.
\end{abstract}

Keywords: Cellulose; Thermal decomposition; Distributed activation energy model (DAEM); Thermogravimetry (TGA); Method of least squares. 


\section{Nomenclature}

$\alpha_{\mathrm{j}}$ reacted fraction of a pseudocomponent

$\beta_{\mathrm{j}}$ parameter expressing the dependence of the preexponential factor on the activation energy $\left(\mathrm{kJ}^{-1} \mathrm{~mol}\right)$

$A_{\mathrm{j}}$ pre-exponential factor $\left(\mathrm{s}^{-1}\right)$

$A_{0, \mathrm{j}}$ value of $A_{\mathrm{j}}$ at $E_{0, \mathrm{j}}$ when $A_{\mathrm{j}}$ was assumed to depend on the activation energy $\left(\mathrm{s}^{-1}\right)$

$c_{\mathrm{j}}$ normalized mass of volatiles formed from a pseudocomponent

$E$ activation energy $(\mathrm{kJ} / \mathrm{mol})$

$E_{0, \mathrm{j}}$ mean activation energy in a distributed activation energy model $(\mathrm{kJ} / \mathrm{mol})$

FWHM full width at half maximum $\left({ }^{\circ} \mathrm{C}\right)$

fit $100 \mathrm{~S}^{0.5}(\%)$

fit $_{1}$, fit $_{3}$, fit 9 fit calculated for 1,3 and 9 experiments, respectively.

$h_{\mathrm{k}}$ height of an experimental curve

$m$ normalized sample mass (dimensionless)

$m^{\text {calc }}(t)$ normalized sample mass calculated from a model

$m^{\mathrm{obs}}(t)$ mass of the sample divided by the initial sample mass

$N_{\mathrm{k}}$ number of evaluated data on the $k$ th experimental curve

$R$ gas constant $\left(8.3143 \times 10^{-3} \mathrm{~kJ} \mathrm{~mol}^{-1} \mathrm{~K}^{-1}\right)$

$\sigma_{\mathrm{E}, \mathrm{j}} \quad$ width parameter (variance) of Gaussian distribution

$S$ least squares sum

$t$ time (s)

$T$ temperature $\left({ }^{\circ} \mathrm{C}, \mathrm{K}\right)$

Subscripts:

i digitized point on an experimental curve

j pseudocomponent

$\mathrm{k}$ experiment

\section{Introduction}

There is a growing interest in biomass fuels and raw materials due to the climatic change problems. The most abundant biomass component is cellulose. There are efforts to find new ways for its utilization as a raw material. One of them is based on a hot pressure treatment (HPT) on cellulose [1]. A heat treatment of a few minutes at $300-350^{\circ} \mathrm{C}$ and $10-15 \mathrm{MPa}$ pressure profoundly changes the properties of cellulose. The HPT celluloses obtained in this way strongly differs from the untreated cellulose. They are suitable for the production of special activated carbons [1]. It is possible that other uses will also be found in the future for this material.

The topic of the present paper is the thermal decomposition kinetics of HPT celluloses. There are a large number of publications on the thermal decomposition kinetics of celluloses and its derivatives from the classical works of Arsenau and Broido to the present [2-5]. However, there is no published data yet 
on HPT celluloses.

In the present work we used a distribution energy model (DAEM). Biomass samples usually contain many different pyrolyizing species. Even the same chemical species may have differing reactivity if their pyrolysis is influenced by other species in their vicinity. Such heterogeneity occurs in other materials, too, e.g. in coals. The assumption of a distribution on the reactivity of the species frequently helps in the description of the pyrolysis of complex organic samples. Usually the activation energies are assumed to have a distribution [6]. The distributed activation energy models (DAEM) have been used for biomass kinetics since 1985 [7-19].

Despites the complicated mathematics of this type of modeling, the works based on DAEM kinetics have usually employed more than one parallel reaction. The resolution of the overlapping curves by parallel DAEM reactions and the finding of a good fit were achieved by a trial-and-error parameter-search in several works $[20,12,13,15]$. Burnham et al. reported a versatile, high-performance computer software in 1987 that was capable for the determination of the unknown model parameters by nonlinear regression [21]. The same software was also able to determine discrete, empirical distribution functions for the activation energy during the evaluation of non-isothermal experiments.

Reynolds, Burnham and Wallman [8,9] studied the pyrolysis decomposition kinetics of cellulose-based materials and determined discrete, empirical distribution functions for the activation energy. They studied the reactivity of paper residues produced by a hydrothermal pretreatment process for municipal solid wastes [9]. The model in this work provided a fit both for the pretreatment and the subsequent rapid pyrolysis.

Miura [22] and Miura and Maki [23] developed methods to determine empirical distribution functions

for $E$ together with a dependence of the preexponential factor on $E$. Their model was employed in studying coals [22-24], biomass [11,17] and other materials [25].

Várhegyi et al. [10] and Becidan et al. [16] based DAEM kinetic studies on the simultaneous evaluation of experiments with linear and stepwise temperature programs. This approach served to increase the available experimental information, as outlined elsewhere [26]. The increase of the information content of the experiments is particularly important when overlapping processes are described by parallel DAEM reactions. The determination of the unknown model parameters and the verification of the model were based on the least-squares evaluation of series of experiments. We follow this approach in the present work. A particular care is taken for employing only a relatively low number of model parameters. This helps to achieve a well-defined parameter estimation. We extend the treatment to the case of nonconstant preexponential factors based on earlier works of Miura [22] and Hashimoto et al. [27].

\section{Experimental}

\subsection{Samples}

A reactor described earlier by Miura et al. [28] were used for the preparation of the samples. Cellulose 
obtained from Nacalai Tesque Company in Japan was loaded into the reactor which was purged with flowing nitrogen during the whole HPT (hot pressure treatment). About $2 \mathrm{~g}$ of cellulose was placed between the molds and gradually heated by an infrared-image furnace at the rate of $10^{\circ} \mathrm{C} / \mathrm{min}$ to the final temperature and hold for $15 \mathrm{~min}$. Mechanical pressure was loaded during this whole process. The cellulose undergoes a partial thermal decomposition with a considerable mass loss under such conditions. The furnace was turned off at the end of the process and the reactor was rapidly cooled down by electric fans. Three samples were selected for the present study from a larger series of experiments. The experimental conditions and the mass loss during the treatment are shown in Table 1.

Table 1. Experimental conditions and overall mass loss during the preparation of the samples

\begin{tabular}{ccccc}
\hline Sample & $\mathrm{T} /{ }^{\circ} \mathrm{C}$ & $\mathrm{P} / \mathrm{MPa}$ & $\mathrm{t} / \mathrm{min}$ & $\begin{array}{c}\text { mass } \\
\text { loss } / \%\end{array}$ \\
\hline 1 & 300 & 10 & 15 & 44 \\
2 & 300 & 15 & 15 & 54 \\
3 & 350 & 10 & 15 & 48 \\
\hline
\end{tabular}

\subsection{TGA experiments}

A Shimadzu TGA-50 apparatus was used. Three different heating programs were used, as shown in Figure 1. The stepwise $T(t)$ consisted of 30 -minute isothermal sections at $350,450,550,650$ and $750^{\circ} \mathrm{C}$, as shown in Fig. 1. (The short drying section at $110^{\circ} \mathrm{C}$ in Fig 1 was outside the domain of kinetic evaluation and has no relevance to the present work.)

The sample mass was around 14,9 and $5 \mathrm{mg}$ in the $5^{\circ} \mathrm{C} / \mathrm{min}$, stepwise and $20^{\circ} \mathrm{C} / \mathrm{min}$ experiments, respectively. The variation of the sample mass with the heating program served to avoid the heat and mass transfer problems at higher heating rates. Each TGA experiment started with a 45-min purge at room temperature to flush out the oxygen traces from the system.

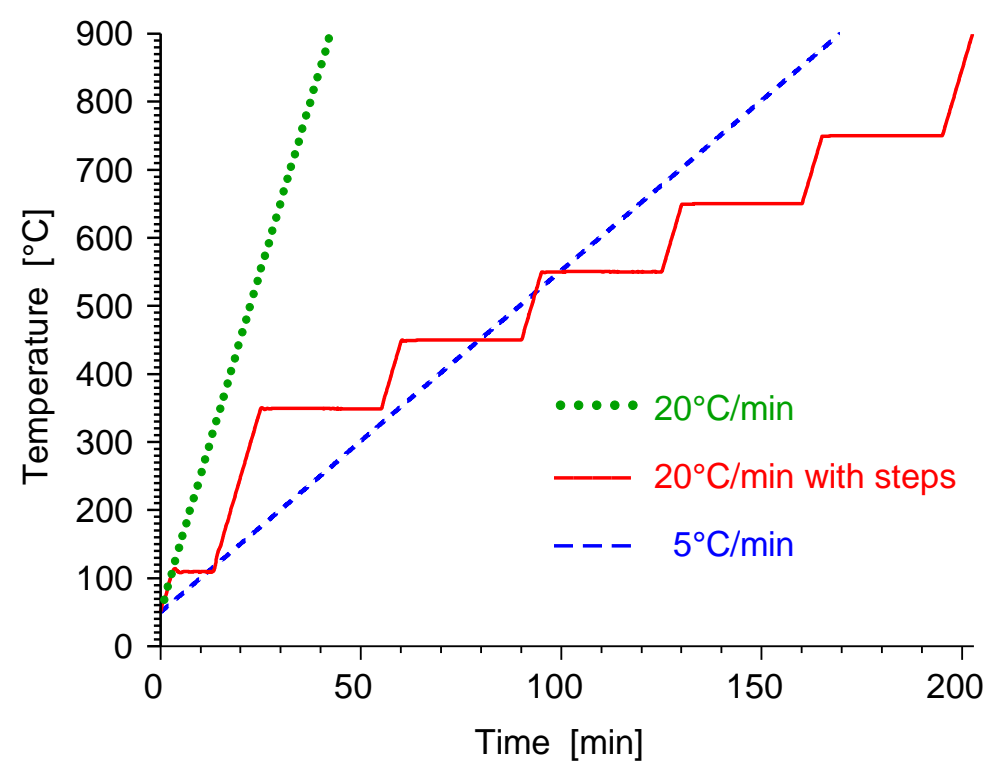

Fig. 1. The temperature programs of the TGA experiments. 


\subsection{Numerical methods}

The derivative of the sample mass curves (DTG) were determined by the analytical differentiation of smoothing splines, as described earlier [29]. The rms difference between the spline function and the measured TGA data was between 0.5 and $0.7 \mu \mathrm{g}$. The differential equations of the model were solved numerically along the empirical temperature - time functions, while the numerical integration of the Gaussian distribution function was approximated by a Gauss-Hermite quadrature formula of 180 points $[10,30]$. The nonlinear least squares minimization was carried out by a variant of the Hook-Jeeves method, which is a slow but simple and dependable direct search algorithm [31]. Note that the rate of convergence is no longer an issue at this size of numerical problems; none of the calculations of this paper needed more than an hour on an ordinary desktop PC. The starting values for the non-linear optimization were taken from earlier work $[10,16]$.

\section{Results and Discussion}

\subsection{Choosing the model}

Figure 2 compares the behavior of the samples at $20^{\circ} \mathrm{C} / \mathrm{min}$ heating rate. The sample with the mildest HPT treatment $\left(300^{\circ} \mathrm{C}\right.$ at $\left.10 \mathrm{MPa}\right)$ exhibit a tall narrow peak and a wide tailing. The other two samples decompose entirely in a wide process from ca. 200 to $800^{\circ} \mathrm{C}$.

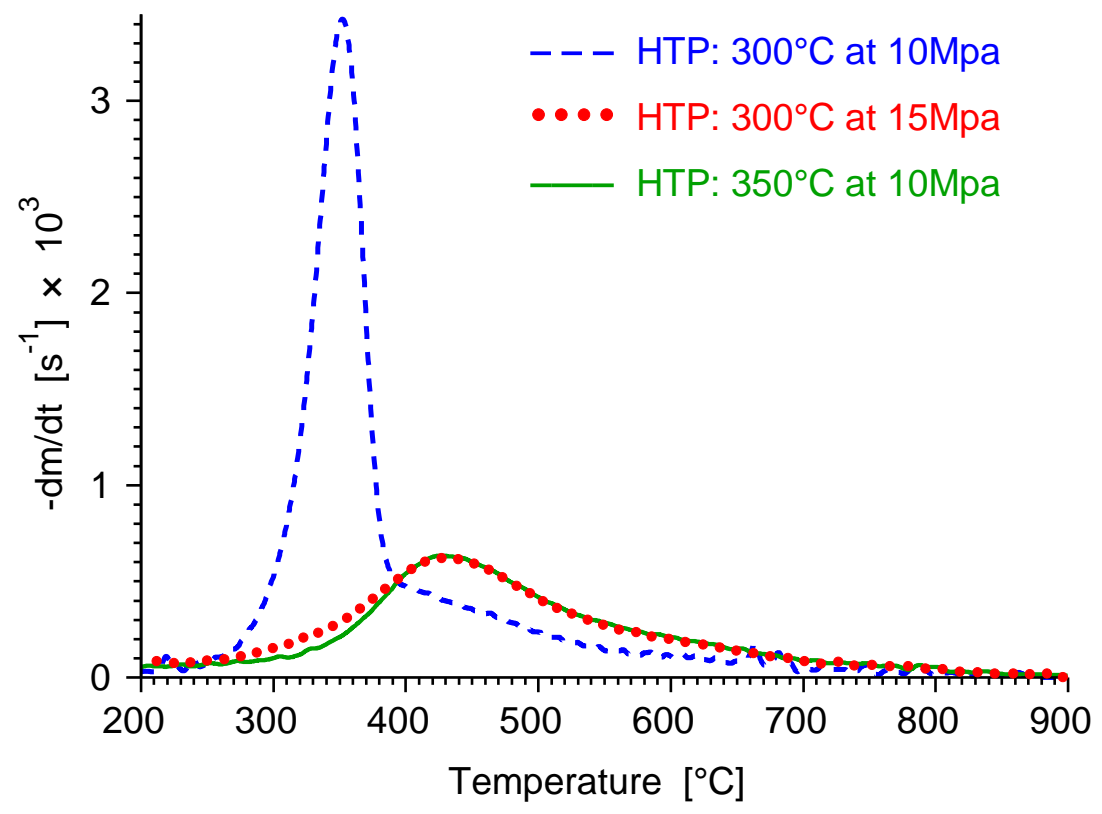

Fig. 2. Mass loss rate curves at $20^{\circ} \mathrm{C} / \mathrm{min}$ heating rate

The sharp peak can be identified with that of the untreated cellulose samples [4]. Accordingly we expect that it can approximately be described by first order kinetics [4]. The wider DTG signals on the figures reflect a large number of partial reactions. In such cases the assumption of distributions on the reactivity of the reacting species frequently gives suitable kinetic approximations, as outlined in the Introduction. We choose the distributed activation energy model with Gaussian distribution. Test 
calculations showed that a model with one DAEM reaction cannot describe well our data. Accordingly we assumed a model of two pseudocomponents. Here a pseudocomponent is the totality of those decomposing species which can be described by the same set of reaction kinetic parameters in the given model. Let $\alpha_{\mathrm{j}}(j=1,2)$ be the reacted fraction of a pseudocomponent and let $\alpha_{\mathrm{j}}(t, E)$ denote the solution of a first order kinetic equation at a given $E$ value:

$$
\mathrm{d} \alpha_{\mathrm{j}}(t, E) / \mathrm{d} t=A_{\mathrm{j}} \mathrm{e}^{-E / R T}\left[1-\alpha_{\mathrm{j}}(t, E)\right]
$$

The reactivity differences of the reacting species within a given pseudocomponent are approximately described by a Gaussian distribution of the activation energy:

$$
D_{\mathrm{j}}(E)=(2 \pi)^{-1 / 2} \sigma_{\mathrm{E}, \mathrm{j}}^{-1} \exp \left[-\left(E-E_{0, \mathrm{j}}\right)^{2} / 2 \sigma_{\mathrm{E}, \mathrm{j}}{ }^{2}\right]
$$

where $E_{0, \mathrm{j}}$ and $\sigma_{\mathrm{E}, \mathrm{j}}$ are the mean value and the width-parameter (variation) of the distribution. The overall reacted fraction of the $j$ th pseudocomponent is obtained by integration:

$$
\alpha_{\mathrm{j}}(t)=\int_{0}^{\infty} D_{\mathrm{j}}(E) \alpha_{\mathrm{j}}(t, E) \mathrm{d} E
$$

The normalized sample mass, $m$, and its derivative are the linear combinations of $\alpha_{\mathrm{j}}(t)$ and $\mathrm{d} \alpha_{\mathrm{j}} / \mathrm{d} t$, respectively:

$$
\begin{aligned}
& -\mathrm{d} m / \mathrm{d} t=c_{1} \mathrm{~d} \alpha_{1} / \mathrm{d} t+c_{2} \mathrm{~d} \alpha_{2} / \mathrm{d} t \\
& m(t)=1-c_{1} \alpha_{1}(t)-c_{2} \alpha_{2}(t)
\end{aligned}
$$

where weight factors $c_{1}$ and $c_{2}$ are equal to the amount of volatiles formed from pseudocomponent 1 and 2 , respectively.

Note that Equations 1 - 3 are equivalent to a first order kinetics at $\sigma_{\mathrm{E}, \mathrm{j}}=0$ since the Gaussian distribution is a well known Dirac delta function.

\subsection{The method of evaluation}

Several experiments (3 - 9) were evaluated simultaneously by the method of least squares. Such kinetic parameters were searched at which the differences between the normalized mass loss rates, $(-d m / d t)^{o b s}$, and their simulated counterparts, $(-d m / d t)^{\text {calc }}$, were small. The following sum was minimized:

$$
\mathrm{S}=\sum_{k=1}^{N_{\text {exp }}} \sum_{i=1}^{N_{k}} \frac{\left[\left(\frac{d m}{d t}\right)_{k}^{o b s}\left(t_{i}\right)-\left(\frac{d m}{d t}\right)_{k}^{c a l c}\left(t_{i}\right)\right]^{2}}{N_{k} h_{k}{ }^{2}}
$$

Subscript $k$ indicates the different experiments. $N_{\exp }$ is the number of experiments evaluated simultaneously, $t_{i}$ denotes the time values in which the digitized $(d m / d t)^{o b s}$ values were taken, and $N_{k}$ is 
the number of the $t_{i}$ points in a given experiment. $h_{k}$ denotes the heights of the evaluated curves that strongly depend on the experimental conditions. The division by $h_{k}{ }^{2}$ serves for normalization. The fit was characterized by the following quantity.

$$
\text { fit }(\%)=100 S^{0.5}
$$

Eq. 7 was also employed to express the fit of a subgroup within the evaluated series of experiments. In such cases, the first summation in Eq. 6 was restricted to the given subgroup. A subgroup may be a single experiment, too. To avoid ambiguity, we shall indicate the number of the corresponding experiments in subscript, as fit 1 , fit 3 , and fit9.

\subsection{Separate kinetic evaluation of the samples}

The model and method outlined above were employed for the three experiments of each sample. The results are shown in Table 2. The calculated and partial curves of this evaluation are not shown in figures since they did not exhibit visible differences from the ones presented in the next section.

Table 2. Kinetic parameters from groups of three experiments ${ }^{\text {a }}$

\begin{tabular}{lrrr}
\hline Pretreatment & $\begin{array}{c}300^{\circ} \mathrm{C} \\
10 \mathrm{MPa}\end{array}$ & $\begin{array}{c}300^{\circ} \mathrm{C} \\
15 \mathrm{MPa}\end{array}$ & $\begin{array}{c}350^{\circ} \mathrm{C} \\
10 \mathrm{MPa}\end{array}$ \\
\hline fit $_{3} / \%$ & 1.21 & 1.39 & 2.22 \\
$E_{0,1} / \mathrm{kJ} \mathrm{s}^{-1}$ & 194.4 & 250.5 & 292.5 \\
$E_{0,2} / \mathrm{kJ} \mathrm{s}^{-1}$ & 238.7 & 237.0 & 243.3 \\
$\sigma_{\mathrm{E}, 1} / \mathrm{kJ} \mathrm{s}^{-1}$ & 0.36 & 18.25 & 18.53 \\
$\sigma_{\mathrm{E}, 2} / \mathrm{kJ} \mathrm{s}^{-1}$ & 34.61 & 50.85 & 45.97 \\
$\log _{10} A_{1} / \mathrm{s}^{-1}$ & 14.52 & 16.62 & 19.69 \\
$\log _{10} A_{2} / \mathrm{s}^{-1}$ & 16.30 & 14.34 & 14.27 \\
$c_{1}$ & 0.39 & 0.15 & 0.13 \\
$c_{2}$ & 0.32 & 0.31 & 0.29 \\
\hline
\end{tabular}

${ }^{a}$ Each sample was evaluated independently from the others. The overall fit of the nine experiments ( $\left.f i t_{9}\right)$ was 1.66 .

\subsection{Joint kinetic evaluation of the nine experiments}

We would like to emphasize that the least squares evaluation does not have maximum likelihood properties in the thermal analysis since the most important experimental errors are not statistical [26]. It is only a practical method to get models that describe well the experiments. Accordingly, one can consider other parameter sets too, if their have more advantageous properties. We were particularly interested in the similarities of the thermal decomposition of these samples. Accordingly we looked for such parameters that express better the similarities and differences of the samples than the ones shown in 


\section{Table 2.}

In this part of the work all the nine experiments were evaluated simultaneously and $\mathrm{E}_{0,1}$ and $\mathrm{E}_{0,2}$ were forced to have common values for the three samples. In this way we determined 20 unknown parameters $\left(2 E_{0, \mathrm{j}}, 6 \sigma_{\mathrm{E}, \mathrm{j}}, 6 A_{\mathrm{j}}\right.$ and $\left.6 c_{\mathrm{j}}\right)$ from 9 experiments. In average 2.1 unknowns fell on an experiment while the number of unknowns was 2.7 per experiment in the calculations of the previous section.

The results are presented in Table 3. As the comparison of Tables 2 and 3 indicate, the fit values became only slightly worse than those of the unconstrained minimization. Figures 3 and 4 show the fit between the calculated and experimental data. The partial curves are also displayed. One can see the very high overlap between the partial curves in Figure 3. According to earlier experience [26] a high number of unknown parameters results in mathematically ill-conditioned least squares evaluations at highly overlapping partial peaks. From this respect, a lower number of unknown parameters is advantageous.

The simultaneous evaluation of the 9 experiments resulted in kinetic parameters that express more clearly the similarities and differences of the samples. Samples 2 and 3 had similar parameter sets in Table 3 while that of Sample 1 differs considerably. When $E_{0, \mathrm{j}}$, is common, $\sigma_{\mathrm{E}, \mathrm{j}}$ influences mainly the width of the curves while $A_{\mathrm{j}}$ are responsible mainly for the peak temperatures: as $A_{\mathrm{j}}$ increases $T_{\text {peak }}$ decreases. The peak width and peak height of the calculated curves at $20^{\circ} \mathrm{C} / \mathrm{min}$ heating rate are presented in Table 4 for both type of evaluations.

Table 3. Kinetic parameters from the simultaneous evaluation of all experiments ${ }^{\text {a }}$

\begin{tabular}{lrrr}
\hline Pretreatment & $\begin{array}{c}300^{\circ} \mathrm{C} \\
10 \mathrm{MPa}\end{array}$ & $\begin{array}{c}300^{\circ} \mathrm{C} \\
15 \mathrm{MPa}\end{array}$ & $\begin{array}{c}350^{\circ} \mathrm{C} \\
10 \mathrm{MPa}\end{array}$ \\
\hline fit $t_{3} / \%$ & 1.37 & 1.51 & 2.57 \\
$E_{0,1} / \mathrm{kJ} \mathrm{s}^{-1}$ & 211.3 & 211.3 & 211.3 \\
$E_{0,2} / \mathrm{kJ} \mathrm{s}^{-1}$ & 265.9 & 265.9 & 265.9 \\
$\sigma_{\mathrm{E}, 1} / \mathrm{kJ} \mathrm{s}^{-1}$ & 1.8 & 15.0 & 12.6 \\
$\sigma_{\mathrm{E}, 2} / \mathrm{kJ} \mathrm{s}^{-1}$ & 39.6 & 56.7 & 49.7 \\
$\log _{10} A_{1} / \mathrm{s}^{-1}$ & 15.99 & 13.62 & 13.52 \\
$\log _{10} A_{2} / \mathrm{s}^{-1}$ & 18.54 & 16.42 & 15.85 \\
$c_{1}$ & 0.39 & 0.15 & 0.13 \\
$c_{2}$ & 0.32 & 0.31 & 0.29 \\
\hline
\end{tabular}

${ }^{\text {a }} E_{0,1}$ and $E_{0,2}$ were forced to have the common values, as described in the text. The overall fit (fitg) was 1.89 . 

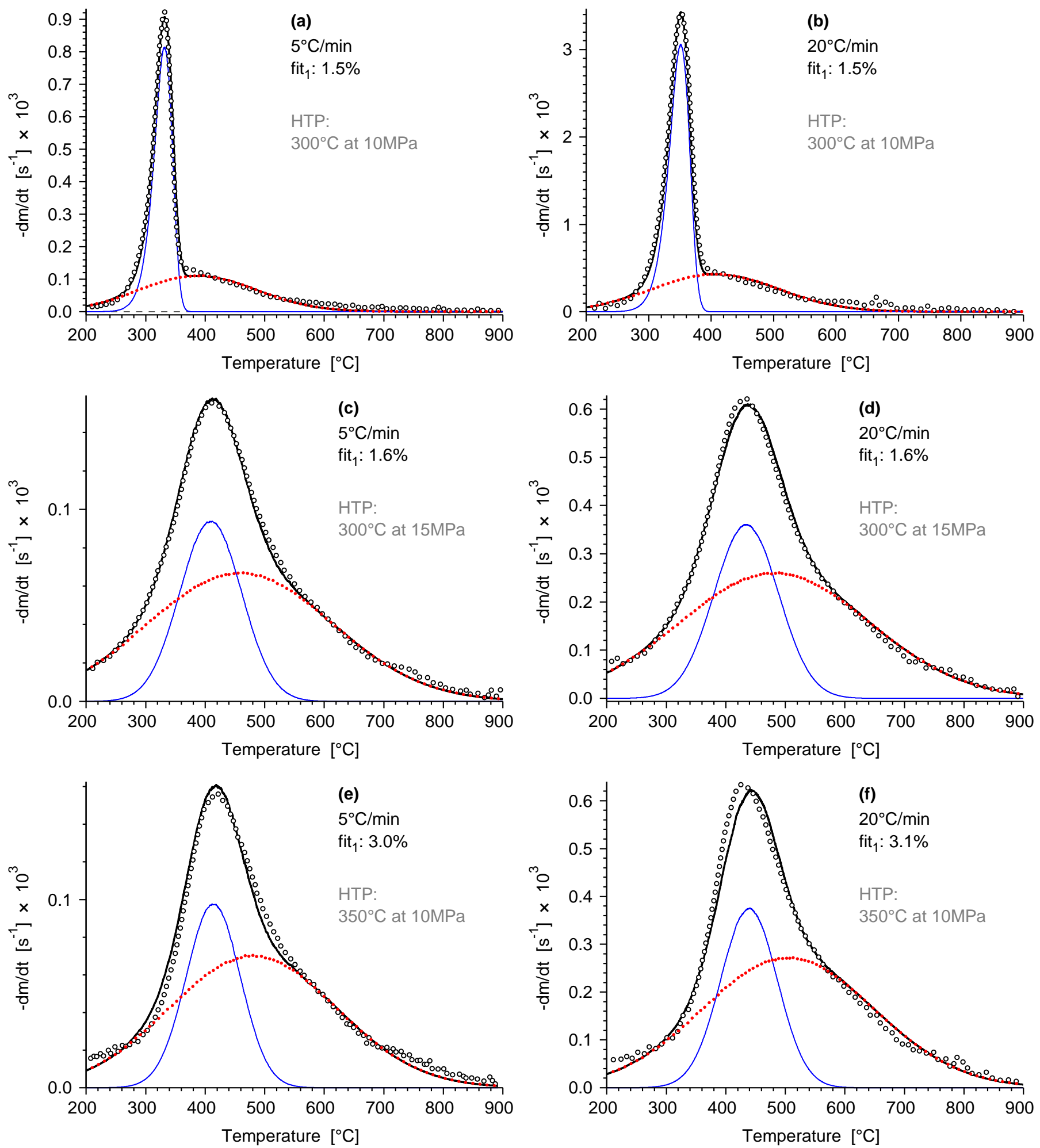

Fig. 3. The constant heating rate experiments in the kinetic evaluation of nine DTG curves by the method of least squares. The experimental curves (o०o), simulated curves (-) and partial curves $(-, \cdots)$ are shown. (See Tables 3 and 4 for kinetic parameters, peak temperatures and peak widths.) 

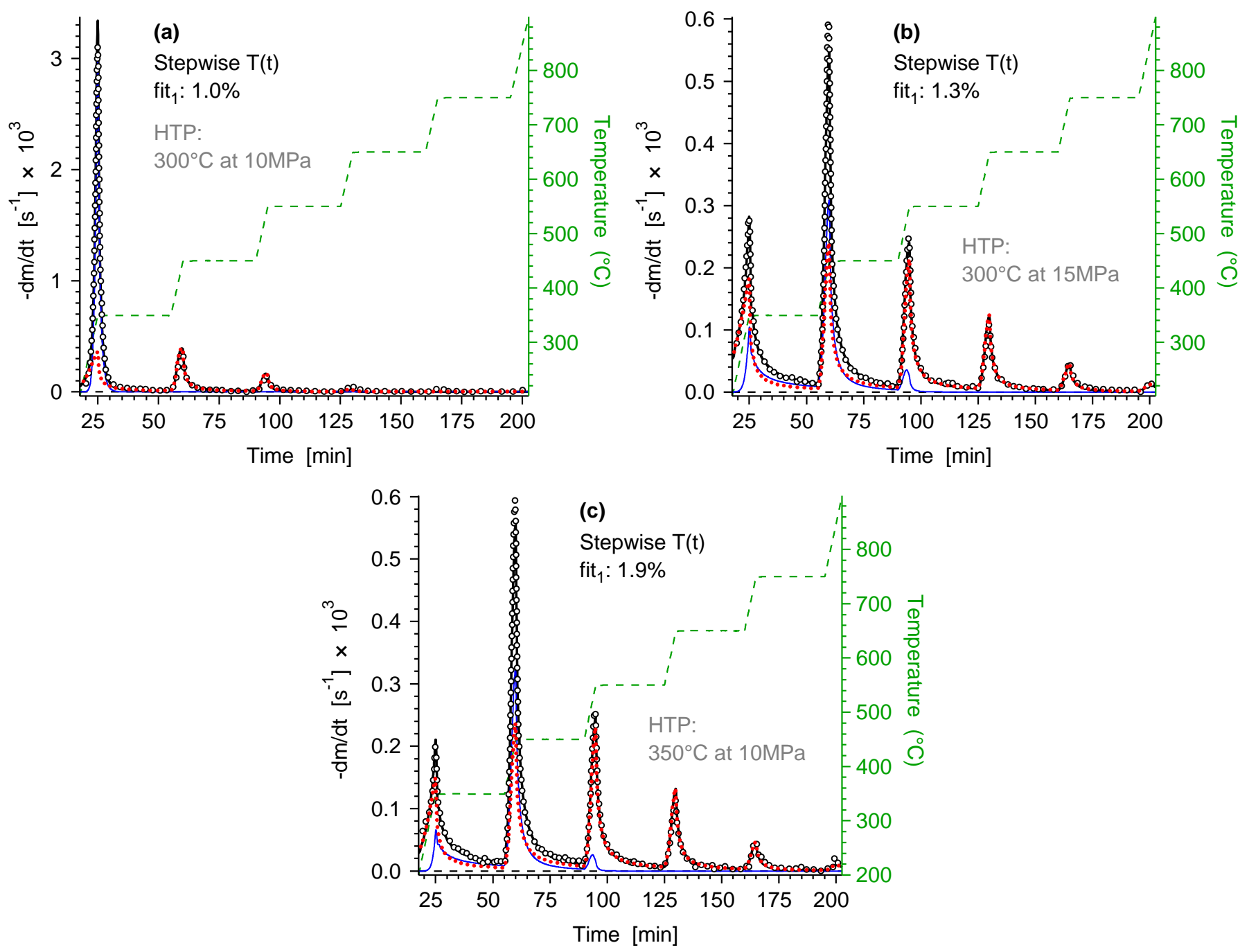

Fig. 4. The experiments with stepwise heating programs in the kinetic evaluation of nine DTG curves by the method of least squares. The experimental curves (ooo), simulated curves (-), partial curves (-, ..) and measured temperatures (---) are shown. (See Tables 3 and 4 for kinetic parameters, peak temperatures and peak widths.)

Table 4. Peak temperatures and peak width of the partial curves simulated for the $20^{\circ} \mathrm{C} / \mathrm{min}$ experiments

\begin{tabular}{lcccccc}
\hline & \multicolumn{3}{c}{$\begin{array}{c}\text { Separate evaluation of the } \\
\text { samples }\end{array}$} & \multicolumn{3}{c}{ Simultaneous evaluation of the } \\
& \multicolumn{3}{c}{ samples } \\
Preatreatment & $\begin{array}{c}300^{\circ} \mathrm{C} \\
10 \mathrm{MPa}\end{array}$ & $\begin{array}{c}300^{\circ} \mathrm{C} \\
15 \mathrm{MPa}\end{array}$ & $\begin{array}{c}350^{\circ} \mathrm{C} \\
10 \mathrm{MPa}\end{array}$ & $\begin{array}{c}300^{\circ} \mathrm{C} \\
10 \mathrm{MPa}\end{array}$ & $\begin{array}{c}300^{\circ} \mathrm{C} \\
15 \mathrm{MPa}\end{array}$ & $\begin{array}{c}350^{\circ} \mathrm{C} \\
10 \mathrm{MPa}\end{array}$ \\
\hline$T_{\text {peak }, 1} /{ }^{\circ} \mathrm{C}$ & 353 & 432 & 438 & 352 & 432 & 441 \\
$T_{\text {peak }, 2} /{ }^{\circ} \mathrm{C}$ & 409 & 490 & 513 & 408 & 491 & 513 \\
$\mathrm{FWHM}_{1} /{ }^{\circ} \mathrm{C}$ & 40 & 127 & 111 & 38 & 127 & 111 \\
$\mathrm{FWHM}_{2} /{ }^{\circ} \mathrm{C}$ & 232 & 376 & 344 & 236 & 373 & 338 \\
\hline
\end{tabular}

The large, sharp peak of Sample 1 at linear $T(t)$ (panels a and b in Fig. 3) is very similar to that of the untreated cellulose. The low $\sigma_{\mathrm{E}, 1}$ value indicate a nearly first order kinetics. It is well known that the cellulose pyrolys kinetics can be well approximated by first order reactions with activation energies 
around the present $E_{0,1}$ value [4]. This behavior shows that a large part of the cellulose has not been transformed during the mildest HPT pretreatment of this study. The second partial peak of this sample can be due to the transformed pat of Sample 1. However, the corresponding peak temperature, $408^{\circ} \mathrm{C}$ at $20^{\circ} \mathrm{C} / \mathrm{min}$ is much lower than the peak temperatures of the other two samples at the same heating rate. (Cf. Table 4.) On the other hand, Samples 2 and 3 revealed remarkable similarities in Figures 3 and 4 as well as in Tables 3 and 4. Keeping in mind the wide temperature interval of their nearly identical thermal behavior, and the striking similarities during the isothermal sections of $350,450,550,650$ and $750^{\circ} \mathrm{C}(\mathrm{Cf}$. Fig. 4), too, these treatments result probably the same chemical structures.

\subsection{Calculations with non- constant preexponential factors}

In 1995 Miura [22] suggested the use of distributed activation energy models with preexponential factors that depend on the activation energy. He used one DAEM reaction and determined tabular and graphic representations for the activation energy distribution and the dependence of the preexponential factor. His approach has been used in several later works including four references of the Introduction $[11,17], 22,25]$.

In this section we shall deal with the application of preexponential factors depending on $\mathrm{E}$. There are essential differences, however, between the evaluation and modeling viewpoints of our approach and that of Miura [22]. The models of the present work are mathematical equations built from analytical expressions. As outlined earlier [26], care is taken for balancing the number of unknown parameters and the available experimental information. In this type of modeling we need a mathematical expression for $A(E)$. Accordingly we tried here an empirical equation from the work of Miura [22] and Hashimoto et al. [27]:

$$
A(E)=\text { const } \exp (\beta E)
$$

We shall apply Eq. 8 to both partial reactions in the following form:

$$
A_{\mathrm{j}}(E)=A_{0, \mathrm{j}} \exp \left[\beta_{\mathrm{j}}\left(E-E_{0, \mathrm{j}}\right)\right] \quad(\mathrm{j}=1,2)
$$

In this notation $A_{0, \mathrm{j}}$ is the preexponential factor at the mean of the $E$ distribution, $E_{0, \mathrm{j}}$. Eq. 1 is written now as

$$
\mathrm{d} \alpha_{\mathrm{j}}(t, E) / \mathrm{d} t=A_{\mathrm{j}}(E) \mathrm{e}^{-E / R T}\left[1-\alpha_{\mathrm{j}}(t, E)\right]
$$

The evaluation was carried out in the same way as in the previous section. The nine experiments were evaluated together with identical $E_{0, \mathrm{j}}$ values. For the values of $\beta_{\mathrm{j}}$ we tried two assumptions:

(i) $\beta_{\mathrm{j}}$ was allowed to depend on the HPT pretreatment of the samples

(ii) common $\beta_{\mathrm{j}}$ values were assumed for the samples.

Table 5 summarizes the results. 
Table 5. Kinetic parameters from the simultaneous evaluation of the nine experiments with preexponential factors depending on $E$

\begin{tabular}{|c|c|c|c|c|c|c|}
\hline Pretreatment & $\begin{array}{c}300^{\circ} \mathrm{C} \\
10 \mathrm{MPa}\end{array}$ & $\begin{array}{c}300^{\circ} \mathrm{C} \\
15 \mathrm{MPa}\end{array}$ & $\begin{array}{c}350^{\circ} \mathrm{C} \\
10 \mathrm{MPa}\end{array}$ & $\begin{array}{c}300^{\circ} \mathrm{C} \\
10 \mathrm{MPa}\end{array}$ & $\begin{array}{c}300^{\circ} \mathrm{C} \\
15 \mathrm{MPa}\end{array}$ & $\begin{array}{c}350^{\circ} \mathrm{C} \\
10 \mathrm{MPa}\end{array}$ \\
\hline Evaluation $^{\mathbf{a}}$ & \multicolumn{3}{|c|}{ common $E_{0,1}$ and $E_{0,2}$} & \multicolumn{3}{|c|}{ common $E_{0,1}, E_{0,2}, \beta_{1}$ and $\beta_{2}$} \\
\hline $\mathrm{fit}_{3} / \%$ & 1.23 & 1.45 & 2.34 & 1.33 & 1.49 & 2.41 \\
\hline$E_{0,1} / \mathrm{kJ} \mathrm{mol}^{-1}$ & 214.5 & 214.5 & 214.5 & 211.8 & 211.8 & 211.8 \\
\hline$E_{0,2} / \mathrm{kJ} \mathrm{mol}^{-1}$ & 266.1 & 266.1 & 266.1 & 275.1 & 275.1 & 275.1 \\
\hline$\sigma_{\mathrm{E}, 1} / \mathrm{kJ} \mathrm{mol}^{-1}$ & 0.7 & 11.2 & 3.6 & 0.8 & 6.1 & 5.2 \\
\hline$\sigma_{\mathrm{E}, 2} / \mathrm{kJ} \mathrm{mol}^{-1}$ & 6.1 & 45.0 & 49.7 & 34.3 & 47.6 & 42.2 \\
\hline$\beta_{1} / \mathrm{kJ}^{-1} \mathrm{~mol}$ & -0.30 & -0.06 & -0.47 & -0.25 & -0.25 & -0.25 \\
\hline$\beta_{2} / \mathrm{kJ}^{-1} \mathrm{~mol}$ & -1.04 & -0.04 & -0.01 & -0.04 & -0.04 & -0.04 \\
\hline $\log _{10} A_{0,1} / \mathrm{s}^{-1}$ & 16.25 & 13.83 & 13.70 & 16.02 & 13.60 & 13.52 \\
\hline $\log _{10} A_{0,2} / \mathrm{s}^{-1}$ & 18.45 & 16.46 & 15.86 & 19.23 & 17.15 & 16.51 \\
\hline$c_{1}$ & 0.37 & 0.13 & 0.14 & 0.39 & 0.14 & 0.13 \\
\hline$c_{2}$ & 0.35 & 0.32 & 0.29 & 0.33 & 0.32 & 0.30 \\
\hline
\end{tabular}

a 9 experiments were evaluated together. The parameters indicated in this line were assumed to have common values for all experiments. Their values are set in italics in the Table. The overall fit (fit ) was 1.74 and 1.80 , respectively.

The comparison of Tables 3 and 5 shows that the fit only slightly improved by the introduction of the $A_{\mathrm{j}}\left(E_{\mathrm{j}}\right)$ dependences. The number of parameters was 20 in Table 3 . When the $\beta_{\mathrm{j}}$ parameters were allowed to depend on the sample properties, the number of parameters went up from 20 to 26, while the overall fit (fitg) changed from 1.89 to 1.74. The assumption of $\beta_{\mathrm{j}}$ parameters independent from the sample properties led to 22 parameters and a fitg of 1.80. Unfortunately we do not have a statistical background to check the statistical significance of these changes in the fit values since the main experimental errors of the thermal analysis are neither random nor independent [26]. From a practical point of view, however, such a low changes in the fit have no importance; they are hardly visible in the figure size of this paper. Figure 5 illustrates the small changes in the calculated curves.

It is interesting to note that the $\sigma_{\mathrm{E}, 1}$ and $\sigma_{\mathrm{E}, 2}$ parameters highly differ in Tables 3 and 5 while the rest of the parameters have similar values. This observation indicates a strong correlation (in other words: a compensation effect) between the $\sigma_{\mathrm{E}, \mathrm{j}}$ and $\beta_{\mathrm{j}}$ parameters. We checked this correlation in test evaluations with fixed $\beta_{\mathrm{j}}=+0.1,-0,1,-0.2$ and -0.3 values. It was found that lower $\beta_{\mathrm{j}}$ values are accompanied by lower $\sigma_{\mathrm{E}, \mathrm{j}}$ values, while the calculated -dm/dt curves do not change considerably, as shown in Figure 5. A closer look on the second partial curve in Figure 5 reveals that the introduction of Eq. 9 into the model slightly alters the shape of the partial curves. It is interesting to note that $\sigma_{\mathrm{E}, 2}$ changed from 40 to 6 $\mathrm{kJ} / \mathrm{mol}$ in that case, 

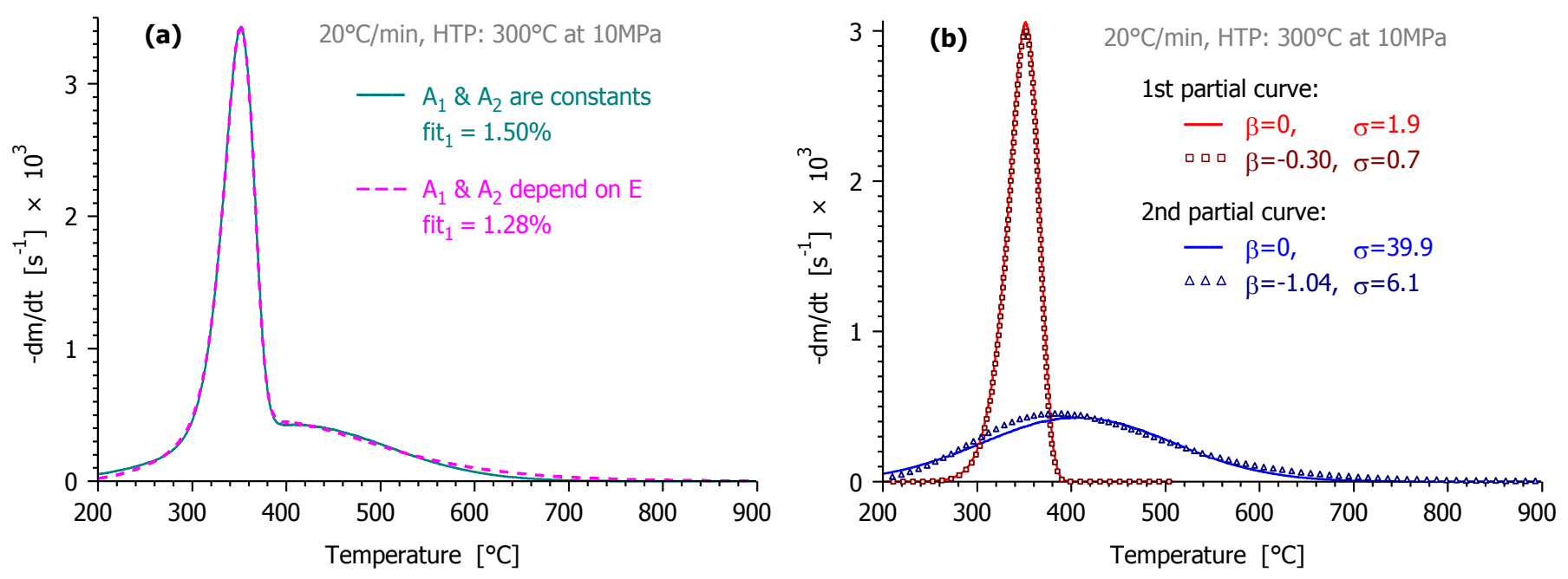

Fig. 5. Comparison of the calculated - $\mathrm{dm} / \mathrm{dt}$ curves (a) and the partial curves (b) at constant and non-constant preexponential factors. The parameter values showing compensation effect are indicated in panel (b). (See the text. Note that the vertical scaling slightly differs in the two plots for a better view.)

\section{Conclusions}

The pyrolysis kinetic of three preprocessed cellulose samples was studied by TGA. Two linear heating rate temperature programs and a stepwise $\mathrm{T}(\mathrm{t})$ function containing 5 isothermal steps were employed. The employed pressurized heat treatment resulted in a material decomposing in a wide temperature range. The distributed activation energy model was used with Gaussian distribution for the pyrolysis kinetics. Two partial reactions were assumed. This model described all of the experiments. The DTG curves were evaluated by the method of least squares. The mean activation energies, $E_{0,1}$ and $E_{0,2}$ were forced to have common values for the three samples. This approach had two benefits: (a) Only 2.1 unknown parameters fell on each experimental DTG curve, meaning that the evaluation became mathematically better conditioned; (b) the obtained parameters reflected better the similarities and the differences of the samples.

The evaluation was also carried out by non-constant preexponential factors that depended on the activation energy. This approach has led only to slight improvement of the fit and revealed a compensation effect between the width of the activation energy distribution and the parameter of the employed $A_{\mathrm{j}}(E)$ function.

The results showed that part of the cellulose remained unconverted and another part only partially converted in mildest pretreatment conditions of this study, $300^{\circ} \mathrm{C}$ at $10 \mathrm{MPa}$. The elevation of the temperature to $350^{\circ} \mathrm{C}$ or the pressure to $15 \mathrm{MPa}$ resulted in a high level of conversion. The thermal behavior of the HPT cellulose obtained in this way differed very much from that of the untreated cellulose. The observations of our study indicate that this relatively simple pretreatment results in a new sort of material. One particular use of this material, its suitability for making activated carbons was shown in an earlier work. We believe that further studies may be beneficial to explore the chemical structure and further application possibilities of the HPT cellulose. 


\section{Acknowledgment}

The authors are grateful for Professor Kouichi Miura and Dr. Ryuichi Ashida for their kind help and advice in this work. The first author, Dr. Wu is particularly grateful for their help during his stay in the Department of Chemical Engineering of the Kyoto University, and for the TGA experiments carried out by Dr. Ashida for this work. We also thank for the support of the Chinese - Hungarian Intergovernmental Science \& Technology Cooperation Program (CHN-35/2005); the Hungarian National Research Fund (OTKA K72710); the National Natural Science Foundation of China (No.20876176); the Scientific Research Foundation for the Returned Overseas Chinese Scholars by the State Education Ministry; The Key Project of Chinese Ministry of Education (No.109100); the Doctoral Project of Shandong Province (2008BS09013); the Research Foundation of Key Laboratory of Carbon Materials, Institute of Coal Chemistry, CAS (KFJJ0506); and the Natural Science Foundation of Shandong Province (Q2007B02).

\section{References}

[1] M. Wu, K. Miura, Q. Zha, J. Qiu, H. Nakagawa, K. Nakagawa, Preparation of high strength and yield activated carbons from waste biomasses by hot pressure treatment, Prepr. Pap.-Am. Chem. Soc., Div. Fuel Chem. 51 (2006), 266-268.

[2] D. F. Arseneau, Competitive reactions in the thermal decomposition of cellulose, Can. J. Chem. 49 (1971) 632-638.

[3] A. Broido, M. Weinstein. Kinetics of solid-phase cellulose pyrolysis, In Proc. 3rd Internat. Conf. Thermal Anal., Wiedemann, Ed., Birkhauser Verlag, Basel, 1971, pp.285-296.

[4] M.J. Antal, Jr., G. Várhegyi, Cellulose pyrolysis kinetics: The current state of knowledge, Ind. Eng. Chem. Res. 34 (1995) 703 - 717.

[5] J. Cai, R. Liu, C. Sun, Logistic regression model for isoconversional kinetic analysis of cellulose pyrolysis, Energy Fuels 22 (2008) 867-870.

[6] A.K. Burnham, R.L. Braun, Global kinetic analysis of complex materials, Energy Fuels 13 (1999) 1-22.

[7] E. Avni, R.W. Coughlin, P.R.Solomon, H.H. King, Mathematical modelling of lignin pyrolysis, Fuel 64 (1985) 1495-1501.

[8] J.G. Reynolds, A.K.Burnham, Pyrolysis decomposition kinetics of cellulose-based materials by constant heating rate micropyrolysis, Energy Fuels 11 (1997) 88-97.

[9] J.G. Reynolds, A.K. Burnham, P.H. Wallman, Reactivity of paper residues produced by a hydrothermal pretreatment process for municipal solid wastes, Energy Fuels 11 (1997), 98-106.

[10] G. Várhegyi, P. Szabó, M. J. Antal, Jr., Kinetics of charcoal devolatilization, Energy Fuels, 16 (2002) 724731.

[11] D. Ferdous, A.K. Dalai, S.K. Bej, R.W. Thring, Pyrolysis of lignins: Experimental and kinetics studies, Energy Fuels 16 (2002) 1405-1412.

[12] W. de Jong, A. Pirone, M.A. Wójtowicz, Pyrolysis of Miscanthus Giganteus and wood pellets: TG-FTIR analysis and reaction kinetics, Fuel 82 (2003) 1139-47.

[13] M.A. Wójtowicz, R. Bassilakis, W.W. Smith, Y. Chen, R.M. Carangelo, Modeling the evolution of volatile species during tobacco pyrolysis, J. Anal. Appl. Pyrolysis, 66 (2003) 235-261. 
[14] A.A. Rostami, M.R. Hajaligol, S.E. Wrenn, A biomass pyrolysis sub-model for CFD applications, Fuel 83 (2004) 1519-25.

[15] W. de Jong, G. Di Nola, B.C.H. Venneker, H. Spliethoff, M.A. Wójtowicz, TG-FTIR pyrolysis of coal and secondary biomass fuels: Determination of pyrolysis kinetic parameters for main species and $\mathrm{NO}_{x}$ precursors, Fuel, 86 (2007) 2367-2376.

[16] M. Becidan, G. Várhegyi, J. E. Hustad, Ø. Skreiberg, Thermal decomposition of biomass wastes. A kinetic study, Ind. Eng. Chem. Res. 46 (2007) 2428 - 2437.

[17] T. Sonobe, N. Worasuwannarak, Kinetic analyses of biomass pyrolysis using the distributed activation energy model, Fuel 87 (2008) 414-421.

[18] J.M. Cai, R.H. Liu, New distributed activation energy model: Numerical solution and application to pyrolysis kinetics of some types of biomass, Bioresource Technol. 99 (2008) 2795-2799.

[19] G. Várhegyi, H. Chen, S. Godoy, Thermal decomposition of wheat, oat, barley and Brassica carinata straws. A kinetic study, Energy Fuels 23 (2009) 646-652.

[20] R. Bassilakis, Y. Zhao, P. R. Solomon, and M. A. Serio, Sulfur and nitrogen evolution in the argonne coals: Experiment and modeling, Energy Fuels 7 (1993) 710-720.

[21] A.K. Burnham, R.L. Braun, H.R. Gregg, Comparison of methods for measuring kerogen pyrolysis rates and fitting kinetic parameters, Energy Fuels 1 (1987) 452-458.

[22] K. Miura, A New and simple method to estimate $f(E)$ and $k_{0}(E)$ in the distributed activation energy model from three sets of experimental data, Energy Fuels 9 (1995) 302-307.

[23] K. Miura, T. Maki, A simple method for estimating $\mathrm{f}(\mathrm{E})$ and $\mathrm{k}_{0}(\mathrm{E})$ in the distributed activation energy model, Energy Fuels 12 (1998) 864-869.

[24] X. Liu, B. Li, K. Miura, Analysis of pyrolysis and gasification reactions of hydrothermally and supercritically upgraded low-rank coal by using a new distributed activation energy model, Fuel Processing Technology 69 (2001) $1-12$.

[25] A. Dawood, K. Miura, Pyrolysis Kinetics of Gamma-irradiated Polypropylene, Polym. Degrad. Stab, 73 (2001) 347-354.

[26] G. Várhegyi, Aims and methods in non-isothermal reaction kinetics, J. Anal. Appl. Pyrolysis 79 (2007) 278288

[27] K. Hashimoto, K. Miura, T. Watanabe, Kinetics of thermal regeneration reaction of activated carbons used in waste water treatment, AIChE J. 28 (1982) 737-746.

[28] K. Miura, H. Nakagawa, H. Okamoto, Production of high density activated carbon fiber by a hot briquetting method, Carbon 38 (2000) 119-125.

[29] G. Várhegyi, F. Till, Computer processing of thermogravimetric - mass spectrometric and high pressure thermogravimetric data. Part 1. Smoothing and differentiation, Thermochim. Acta, 329 (1999) 141-145.

[30] E. Donskoi; D.L.S. McElwain, Optimization of coal pyrolysis modeling, Combust. Flame, 122 (2000) 359367.

[31] T.G. Kolda, R.M. Lewis, V. Torczon, Optimization by direct search: New perspectives on some classical and modern methods, SIAM Review 45 (2003) 385-482. 